\title{
Induction of resistance to Pyricularia oryzae in wheat by acibenzolar-S-methyl, ethylene and jasmonic acid
}

\author{
Jonas Alberto Rios, Fabrício Ávila Rodrigues, Daniel Debona, Renata Sousa Resende, Wiler Ribas \\ Moreira \& Camila Cristina Lage Andrade
}

Departamento de Fitopatologia, Laboratório da Interação Planta-Patógeno, Universidade Federal de Viçosa, 36570-900, Viçosa, MG, Brazil

Author for correspondence: Fabrício Ávila Rodrigues, e-mail: fabricio@ufv.br

\begin{abstract}
This study investigated the effects of acibenzolar-S-methyl (ASM), ethylene (ET) and jasmonic acid (JA) on the resistance of two wheat cultivars (BRS-229 and BR-18) to infection by Pyricularia oryzae. The treatments included spraying plants with ASM (300 $\left.\mathrm{mg} \mathrm{L}^{-1}\right)$, ET $(0.5 \mathrm{mM})$, JA $(0.1 \mathrm{mM})$ and distilled water (control) $48 \mathrm{~h}$ before inoculation with $P$. oryzae. Malondialdehyde concentration, an indicative of oxidative damage to the lipids in the leaf cells, was significantly higher for plants sprayed with ASM compared to plants sprayed with JA and ET. Plants sprayed with JA and ET showed reduced values for the number of lesions per $\mathrm{cm}^{2}$ of leaf area and area under blast progress curve, but these hormones had no effect on the incubation period and lesion size (in mm). Plants sprayed with JA and ET showed reduce blast symptoms in comparison to plants sprayed with ASM due to greater peroxidase, polyphenoloxidase, chitinase and $\beta$-1,3-glucanase activities.
\end{abstract}

Key words: Triticum aestivum, blast, hormones, host defense responses.

\section{INTRODUCTION}

Wheat (Triticum aestivum L.) is one of the most important cereals for the world population (Arruda et al., 2005) and the occurrence of diseases is the biggest factor that impedes to achieve high yield. Wheat blast, caused by the fungus Pyricularia oryzae (Cooke) Sacc., can cause yield loss of approximately $70 \%$ (Goulart \& Paiva, 2007). The fungus can infect all aerial organs of the plants, including leaves, culms and cobs (Igarashi et al., 1986). On leaves, the symptoms are elliptical or rounded lesions with dark brown margins and gray center (Goulart \& Paiva, 2007). In the ears, the symptoms are very distinctive, occurring bleaching and death of the tissue in the infection site and darkening of the rachis (Goulart \& Paiva, 2007). Grains can become wrinkled, deformed and lower in size and weight when fungal infection occurs on ears (Goulart \& Paiva, 2007). The favorable conditions for blast epidemics are rainy periods, temperatures ranging from 21 to $27^{\circ} \mathrm{C}$, cloudy days and high relative humidity (Goulart \& Paiva, 2007). The chemical control has low efficiency in controlling blast (Goulart \& Paiva, 2007) and cultivars with desirable levels of resistance to the disease are not available yet (Urashima et al., 2004).

Plants are able to enhance their level of basal resistance against pathogen attack through a phenomenon known as induced resistance, which can be achieved by different abiotic and biotic stimuli (Pieterse et al., 2012). The classic examples of inducible plant defense are systemic acquired resistance (SAR) and induced systemic resistance (ISR), which differ according to the nature of the elicitor and the regulatory pathways involved (Knoester et al., 1999). In general, SAR is related to the production of pathogenesis-related proteins (PR-proteins) and is salicylic acid (SA) dependent (Knoester et al., 1999). In contrast, ISR is not related to PR-protein accumulation, is induced by nonpathogenic microorganisms and is signaled via ethylene (ET) and jasmonic acid (JA) (Knoester et al., 1999). However, several recent studies have shown that these signaling pathways do not function independently but, rather, influence each other through a complex network of synergistic and antagonistic interactions (Conrath, 2006). Acibenzolar-S-methyl (ASM), an analog of salicylic acid, and JA and ET are known to play roles in the signaling pathways that result in the induction of host resistance (Glazebrook, 2005). JA is very important in solanaceous resistance to diseases because of its potential to trigger both local and systemic protection (Cohen et al., 1993). Vine leaves sprayed with ester methyl jasmonate (MeJA) show an increase in the activities of chitinase, glucanase, stilbene synthase and phenylalanine ammonia-lyase (Belhadj et al., 2006). In addition to plant responses to abiotic and biotic stress, ET is involved in seed emergence, leaf and flower senescence, fruit ripening and organ abscission (Abeles, 1992). Indeed, ET plays an important role in increasing host resistance to diseases mainly through an increase in the concentrations of phytoalexins, lignin and phenolic compounds and in the activity of chitinase, phenylalanine 
ammonia-lyase and peroxidase (Khoel et al., 2002). An increase in the endogenous levels of SA in plants infected with pathogens is associated with the elevated expression of genes encoding for PR-proteins (Conrath, 2006).

Considering the low efficiency of fungicides and the absence of wheat cultivars with satisfactory levels of resistance to blast, the use of inducers of resistance has become an alternative to reduce the yield losses caused by this disease. Therefore, this study aimed to investigate the effect of ASM, ET and JA on the induction of wheat resistance against infection by $P$. oryzae.

\section{MATERIAL AND METHODS}

\section{Plant growth}

Wheat seeds from cultivars BR-18 and BRS-229 were surface-sterilized in $10 \% \mathrm{NaOCl}$ for $2 \mathrm{~min}$, rinsed in sterilized water for $3 \mathrm{~min}$, and sown in plastic pots $(20-\mathrm{cm}$ diameter) (Ecovaso) filled with $1 \mathrm{~kg}$ of substrate made from a 1:1:1 mixture of pine bark, peat and expanded vermiculite (Tropstrato; Vida Verde). These cultivars are susceptible and partially resistant to leaf blast at the vegetative growth stage (Debona et al., 2012). A total of $1.63 \mathrm{~g}$ of calcium phosphate monobasic was added to each plastic pot. A total of twelve seeds were sown per pot and five days after seedling emergence, each pot was thinned to two seedlings. The substrate in each pot was fertilized with a nutrient solution containing the following in $\mathrm{g} \mathrm{L}^{-1}: 6.4 \mathrm{KCl}, 3.48 \mathrm{~K}_{2} \mathrm{SO}_{4}, 5.01$ $\mathrm{MgSO}_{4} \cdot 7 \mathrm{H}_{2} \mathrm{O}, 2.03\left(\mathrm{NH}_{2}\right)_{2} \mathrm{CO}, 0.009 \mathrm{NH}_{4} \mathrm{MO}_{7} \mathrm{O}_{24} \cdot 4 \mathrm{H}_{2} \mathrm{O}$, $0.054 \mathrm{H}_{3} \mathrm{BO}_{3}, 0.222 \mathrm{ZnSO}_{4} \cdot 7 \mathrm{H}_{2} \mathrm{O}, 0.058 \mathrm{CuSO}_{4} .5 \mathrm{H}_{2} \mathrm{O}$ and $0.137 \mathrm{MnCl}_{2} \cdot 4 \mathrm{H}_{2} \mathrm{O}$ (Debona et al., 2012). A volume of 15 $\mathrm{mL}$ of nutrient solution containing $0.27 \mathrm{~g} \mathrm{~L}^{-1} \mathrm{FeSO}_{4} .7 \mathrm{H}_{2} \mathrm{O}$ and $0.37 \mathrm{~g} \mathrm{~L}^{-1}$ EDTA bisodic $\mathrm{L}^{-1}$ was also applied after seedlings emergence. The nutrient solution was prepared using deionized water. After seedling emergence, $30 \mathrm{ml}$ of the nutrient solution was applied to each pot every week. The plants were watered as needed with deionized water.

\section{Application of resistance inducers}

The treatments used were T1 - distilled water(control), T2 - $0.1 \mathrm{mM}$ jasmonic acid (JA) (Sigma-Aldrich), T3 - 300 $\mathrm{mg} \mathrm{L}^{-1}$ acibenzolar-S-methyl (ASM) (Bion; Syngenta) and T4 - $0.5 \mathrm{mM}$ Ethephon (2-chloroethyl phosphonic acid) (ET) (Sigma-Aldrich). The plants were sprayed with distilled water and with the inducers using a manual atomizer 48 $\mathrm{h}$ prior to inoculation with $P$. oryzae. The plants from the replications of each treatment were maintained in separate growth chambers during the application of the inducers and then transferred to independent chambers for $6 \mathrm{~h}$.

\section{Inoculation of plants with P. oryzae}

Plants were inoculated with a conidial suspension of $P$. oryzae $\left(10^{5}\right.$ conidia $\left.\mathrm{mL}^{-1}\right)$ at 30 days after emergence (growth stage 19) (Zadoks, 1974). Twenty-five milliliters of suspension was applied as a fine mist to the adaxial leaf blades of each plant until runoff using a VL Airbrush atomizer (Paasche Airbrush Co.). Gelatin (1\%) was added to the suspension to aid conidial adhesion to the leaf blades. Immediately after inoculation, the plants were transferred to a growth chamber with a temperature of $25 \pm 2^{\circ} \mathrm{C}$ and a relative humidity of $90 \pm 5 \%$ and were subjected to an initial $24 \mathrm{~h}$ dark period. After this period, the plants were transferred to a plastic mist growth chamber (MGC) inside a greenhouse for the duration of the experiment. The MGC was made of wood ( $2 \mathrm{~m}$ wide, $1.5 \mathrm{~m}$ high and $5 \mathrm{~m}$ long) and covered with $100-\mu \mathrm{m}$ thick transparent plastic. The temperature inside the MGC ranged from $25 \pm 2^{\circ} \mathrm{C}$ (day) to $20 \pm 2^{\circ} \mathrm{C}$ (night). The relative humidity was maintained at $92 \pm 3 \%$ using a misting system in which nozzles (model NEB-100; KGF Company) sprayed mist every 30 min above the plant canopy. The relative humidity and temperature were measured with a TH-508 thermo-hygrograph (Impac). The maximum natural photon flux density at plant canopy height was approximately $900 \mu \mathrm{mol} \mathrm{m}{ }^{-2} \mathrm{~s}^{-1}$.

\section{Quantification of the components of resistance}

The incubation period (IP), number of lesions (NL) per $\mathrm{cm}^{2}$ of leaf area, lesion size (LS) and blast severity were assessed in the fourth, fifth and sixth leaves (from the base to the top) of each plant. IP was assessed every $6 \mathrm{~h}$ from 24 $\mathrm{h}$ after inoculation (hai). At 96 hai, the number of lesions per $\mathrm{cm}^{2}$ of leaf area was determined at three locations randomly chosen on each leaf. LS, in mm, was measured at 96 hai with the aid of a digital caliper (Worker). Three lesions randomly selected on the leaves of each plant were selected to perform the measurements. Blast severity was assessed at 72, 96, 120 and 144 hai using the scale proposed by Rios et al. (2013). The area under blast progress curve (AUBPC) for each plant was calculated using the trapezoidal integration of the blast progress curves, according to Shaner \& Finney (1997).

\section{Determination of the concentration of malondialdehyde (MDA)}

Leaf samples from one plant per replication and treatment were collected at 48, 72, 96 and 120 hai; leaf samples were also collected from non-inoculated plants $(0 \mathrm{~h})$. The leaf samples were placed in liquid nitrogen $\left(\mathrm{N}_{2}\right)$ during sampling and then stored at $-80^{\circ} \mathrm{C}$ until further analysis. Oxidative damage to the lipids in the leaf cells was estimated as the content of total 2-thiobarbituric acid (TBA) reactive substances and expressed as malondialdehyde (MDA) equivalents, according to Cakmak \& Horst (1991), with a few modifications. Briefly, leaf tissue was ground into a fine powder in liquid nitrogen using a mortar and pestle, and the powder was homogenized in $2 \mathrm{ml} 0.1 \%\left(\mathrm{w} \mathrm{V}^{-1}\right)$ trichloroacetic acid (TCA) solution at $4^{\circ} \mathrm{C}$. After centrifugation at $10000 \mathrm{~g}$ for $15 \mathrm{~min}, 250 \mu \mathrm{L}$ of the supernatant was mixed with 750 $\mu \mathrm{L}$ of TBA $(0.5 \%$ in $20 \% \mathrm{TCA})$ for $2 \mathrm{~h}$ in a boiling water bath. The reaction was stopped in an ice bath. The samples were centrifuged at $13000 \mathrm{~g}$ for $4 \mathrm{~min}$, and the absorbance of the supernatant was measured at $540 \mathrm{~nm}$ (Evolution 60; 
Thermo Scientific). The concentration of MDA formed in each sample was calculated using the extinction coefficient of $155 \mathrm{mM}^{-1} \mathrm{~cm}^{-1}$, and the concentration was expressed as $\mu$ mol MDA g ${ }^{-1}$ of fresh matter (FM).

Determination of the activities of peroxidase (POX, EC1.11.1.7), polyphenoloxidase (PPO, EC 1.10.3.1) phenylalanine ammonia-lyase (PAL, EC 4.3.1.5), chitinase (CHI, EC 3.2.1.14), $\beta$-1,3-glucanase (GLU, EC 3.2.1.39) and lypoxigenase (LOX, EC 1.13.11.12)

Leaf samples from one plant per replication and treatment were collected at 48, 72, 96 and 120 hai. Leaf samples were also collected from non-inoculated plants $(0$ h). The leaf samples were kept in liquid $\mathrm{N}_{2}$ during sampling and then stored at $-80^{\circ} \mathrm{C}$ until further analysis. To obtain the extracts used to determine the activities of POX, PPO, PAL, $\mathrm{CHI}$ and GLU, $0.2 \mathrm{~g}$ of leaf tissue was macerated with liquid $\mathrm{N}_{2}$ in a mortar with the addition of polyvinylpyrrolidone (PVP) $1 \%\left(\mathrm{w} \mathrm{V}^{-1}\right)$ to obtain a fine powder. The powder was homogenized in $2 \mathrm{~mL}$ of $50 \mathrm{mM}$ sodium phosphate (pH 6.5) containing $1 \mathrm{mM}$ phenylmethylsulfonicfluoride (PMSF) and $0.1 \mathrm{mM}$ acid etilenodiaminotetracetic (EDTA). The homogenized material was centrifuged at 20,000 $\mathrm{g}$ for 25 min at $4^{\circ} \mathrm{C}$ and the supernatant was used for enzyme determination.

POX and PPO activities were determined by the oxidation of pyrogallol according to the method of Kar \& Miashra (1976). For POX activity, a mixture of $300 \mu \mathrm{L}$ of distilled water, $250 \mu \mathrm{L}$ of $100 \mathrm{mM}$ potassium phosphate buffer (pH 6.8), $200 \mu \mathrm{L}$ of $100 \mathrm{mM}$ pyrogallol and $200 \mu \mathrm{L}$ of $100 \mathrm{mM}$ hydrogen peroxide was added to $50 \mu \mathrm{L}$ of the extract. For PPO activity, the mixture was composed of 300 $\mu \mathrm{L}$ of distilled water, $250 \mu \mathrm{L}$ of $100 \mathrm{mM}$ potassium phosphate buffer (pH 6.8) and $200 \mu \mathrm{L}$ of $100 \mathrm{mM}$ pyrogallol, which was added to $50 \mu \mathrm{L}$ of the extract. The absorbance was measured in spectrophotometer at $420 \mathrm{~nm}$ every 10 seconds for $1 \mathrm{~min}$ after addition of the extract to the mixture in a total of five readings. A molar extinction coefficient of 2.47 $\mathrm{mM}^{-1} \mathrm{~cm}^{-1}$ was used to calculate POX and PPO activities, which were expressed in mmol purpurogallin produced mmol $\mathrm{min}^{-1} \mathrm{mg}^{-1}$ protein.

PAL activity was determinate adding $0.1 \mathrm{~mL}$ of the extract to a mixture containing $0.5 \mathrm{~mL}$ of Tris- $\mathrm{HCl}(\mathrm{pH}$ $8.8,25 \mathrm{mM}$ ) and $0.4 \mathrm{~mL}$ of $100 \mathrm{mM} L$-phenylalanine. The reaction mixture was incubated in a water bath at $30^{\circ} \mathrm{C}$ for $3 \mathrm{~h}$. In the control samples, $L$-phenylalanine was replaced with Tris- $\mathrm{HCl}$ buffer. The reaction was finalized by adding $0.1 \mathrm{~mL}$ of $6 \mathrm{~N} \mathrm{HCl}$. The absorbance of the trans-cinnamic acid derivatives was measured in a spectrophotometer at $290 \mathrm{~nm}$ and a molar extinction coefficient of $10^{4} \mathrm{mM}^{-1} \mathrm{~cm}^{-1}$ was used to calculate PAL activity, which was expressed in

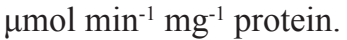

The enzyme extracts for CHI were prepared following the method of Harman et al. (1993) with a few modifications. The reaction was started by the addition of $20 \mu 1$ of crude enzyme extract to a mixture containing 480 $\mu 150 \mathrm{mM}$ sodium acetate buffer ( $\mathrm{pH}$ 5.0) and $p$-nitrofenil$\beta$-D-N-N'-diacetilquitobiose (Sigma-Aldrich) at $2 \mathrm{mg}$ $\mathrm{ml}^{-1}$. The reaction mixture was incubated in a water bath at $37^{\circ} \mathrm{C}$ for $2 \mathrm{~h}$. Adding $500 \mu \mathrm{L}$ of $0.2 \mathrm{M}$ sodium carbonate terminated the reaction. The absorbance of the end products released by the CHI present in the crude enzyme extract was recorded at $410 \mathrm{~nm}$. An extinction coefficient of $7 \times 10^{4}$ $\mathrm{mM}^{-1} \mathrm{~cm}^{-1}$ was used to calculate $\mathrm{CHI}$ activity, which was expressed as mmol of $p$-nitrophenyl $\mathrm{min}^{-1} \mathrm{mg}^{-1}$ protein.

GLU activity was determined as described by Lever (1972). The reaction was initiated by the addition of $20 \mu \mathrm{L}$ aliquots of the supernatant to a mixture of $230 \mu \mathrm{L}$ of 100 $\mathrm{mM}$ sodium acetate (pH 5.0) and $250 \mu \mathrm{L}$ of the substrate laminarin (Sigma-Aldrich) in a concentration of $4 \mathrm{mg} \mathrm{mL}^{-1}$. The reaction mixture was incubated in a water bath for $30 \mathrm{~min}$ at $45^{\circ} \mathrm{C}$. After the incubation period, the amount of reducing sugars was determined by adding $500 \mu \mathrm{L}$ of dinitrosalicylic acid to the mixture and then incubating the resulting mixture in a water bath for $15 \mathrm{~min}$ at $100^{\circ} \mathrm{C}$. The reaction was interrupted by cooling the samples in an ice bath. In the control samples, the reaction mixture was the same, except that the extract was added after heating the mixture at $100^{\circ} \mathrm{C}$. The absorbance of the product released by GLU was measured at $540 \mathrm{~nm}$ and the activity of GLU was expressed in absorbance $\mathrm{min}^{-1} \mathrm{mg}^{-1}$ of protein.

To obtain the extract for enzymatic determination of LOX, $0.2 \mathrm{~g}$ of leaf tissue was macerated with liquid $\mathrm{N}_{2}$ in a mortar to obtain a fine powder. The powder was homogenized in $2 \mathrm{~mL}$ buffer of $20 \mathrm{mM}$ sodium phosphate (pH 6.8) containing Triton-X $1 \%\left(\mathrm{v} \mathrm{v}^{-1}\right)$ and PVP $1 \%(\mathrm{w}$ $\mathrm{V}^{-1}$ ). The homogenized material was centrifuged at $15,000 \mathrm{~g}$ for $20 \mathrm{~min}$ at $4^{\circ} \mathrm{C}$. The supernatant was used as the extract for the determination of LOX activity. The reaction was started by adding $5 \mu \mathrm{L}$ of the extract to a mixture containing $780 \mu \mathrm{L}$ of buffer $50 \mathrm{mM}$ sodium phosphate (pH 6.5) and 15 $\mu \mathrm{L}$ of $10 \mathrm{mM}$ sodium linoleate substrate. LOX activity was determined according to the method described by Axelrod et al. (1981). The absorbance of the product released by LOX was measured in a spectrophotometer at $234 \mathrm{~nm}$. A molar extinction coefficient of $25,000 \mathrm{M}^{-1} \mathrm{~cm}^{-1}$ was used to determine LOX activity, which was expressed as $\mu \mathrm{mol}$ $\mathrm{min}^{-1} \mathrm{mg}^{-1}$ protein.

The protein concentration in each sample was determined according to the method of Bradford (1976).

\section{Experimental design and statistical analysis}

Two $2 \times 4$ factorial experiments consisting of two cultivars and the inducers (ASM, AJ and ET) plus distilled water (control treatment) were arranged in a completely randomized design, with four replications. Each experimental unit consisted of one plastic container with two plants. Data for IP, NL, LS and AUBPC of the two experiments were combined for the statistical analysis after determining the homogeneity of variance (Gomes \& Garcia, 2002). Only one experiment was performed for the biochemical evaluations. Data for the MDA concentration 
and POX, PPO, PAL, CHI, GLU and LOX activities were subjected to an analysis of variance, and the treatment means were compared using Tukey's test $(P \leq 0.05)$ with SAS software (SAS Institute).

\section{RESULTS}

\section{Components of resistance}

The factors cultivar and inducer were significant for IP, NL and AUBPC and the interaction cultivar $\times$ inducer for NL. There was no significant difference between the cultivars with regard to IP, LS and AUBPC (Table 1). NL was significantly higher for cultivar BRS-229 in comparison to cultivar BR-18 (Table 1). There was no significant difference among the treatments of distilled water, JA, ASM and ET for IP and LS (Table 1). NL was significantly reduced by $66.8,38.9$ and $67.43 \%$, respectively, with the JA, ASM and ET treatments in comparison to the distilled water treatment (Table 1). There was a significant decrease of 55, 35 and $60 \%$ for AUBPC, respectively, for the treatments of JA, $\mathrm{ASM}$ and ET in comparison to the distilled water treatment (Table 1).

\section{MDA concentration}

The factors inducer and sampling time and the interaction inducer $\times$ sampling time were significant. The MDA concentration for the plants sprayed with ASM was significantly higher compared to the other treatments at 0 , 72,96 and 120 hai for BRS-229 and at 0, 48, 72 and 96 hai for BR-18 (Table 2). There was no significant difference between the plants of cultivar BR-18 sprayed with ASM or distilled water at 120 hai (Table 2).

TABLE 1 - Incubation period (IP), number of lesions (NL) per $\mathrm{cm}^{2}$ of leaf area, lesion size (LS) and area under blast progress curve (AUBPC) on wheat plants from cultivars BRS-229 and BR18 sprayed with distilled water, jasmonic acid (JA), acibenzolar-Smethyl (ASM) and ethylene (ET) and inoculated with Pyricularia oryzae.

\begin{tabular}{lcrcc}
\hline \hline \multirow{2}{*}{ Factors } & \multicolumn{5}{c}{ Components of Resistance } \\
\cline { 2 - 5 } & IP (h) & NL & LS (mm) & AUBPC \\
\hline Cultivars & & & & \\
BRS-229 & 62.46 & 14.21 & 1.62 & 532.48 \\
BR-18 & 61.96 & 10.40 & 1.59 & 510.48 \\
$F$ values & $1.73^{\text {ns }}$ & $2.09^{*}$ & $1.50^{\text {ns }}$ & $1.23^{\text {ns }}$ \\
Inducers & & & & \\
Distilled water & $61.31 \mathrm{a}$ & $21.71 \mathrm{a}$ & $1.71 \mathrm{a}$ & $834.25 \mathrm{a}$ \\
JA & $63.18 \mathrm{a}$ & $7.19 \mathrm{c}$ & $1.57 \mathrm{a}$ & $375.21 \mathrm{c}$ \\
ASM & $61.59 \mathrm{a}$ & $13.26 \mathrm{~b}$ & $1.55 \mathrm{a}$ & $542.77 \mathrm{~b}$ \\
ET & $63.65 \mathrm{a}$ & $7.07 \mathrm{c}$ & $1.50 \mathrm{a}$ & $333.70 \mathrm{c}$ \\
\hline CV (\%) & 5.08 & 16.05 & 19.74 & 5.46
\end{tabular}

Means within a column followed by the same letter are not significantly different $(P=0.05)$ according to the Tukey's test.

$\mathrm{CV}$, coefficient of variation; *, significant at $\mathrm{P} \leq 0.05$; ns, non significant.

\section{Activity of defense enzymes}

The cultivar factor was significant for POX, PPO, $\mathrm{CHI}$ and LOX. The inducer factor was not significant for CHI and GLU, and the sampling time factor was not significant for CHI. Some interactions with two and three factors were also significant. For BRS-229, there was no significant difference for POX activity among the JA, ASM and ET treatments at 0, 48, 72 and 96 hai (Table 3). POX activity significantly increased in the plants sprayed with JA compared to the control treatment at 0 hai, JA, ASM and ET at 48 hai, ASM and ET at 72 hai and ET at 120 hai. No significant difference in POX activity occurred between the treatments at 96 hai (Table 3). For cultivar BR-18, there was no significant difference among the treatments for POX activity at 0,48 and 96 hai (Table 3 ). At 72 hai, there was no significant difference among the JA, ASM and ET treatments with regard to POX activity. POX activity was significantly higher with the JA and ET treatments compared to the ASM treatment at 120 hai. There was no significant difference in POX activity for the JA, ASM and ET treatments in relation to the control treatment at 120 hai (Table 3).

For BRS-229, there was no significant difference among the treatments at 0,48 and 120 hai with regard to PPO activity (Table 4). PPO activity was significantly greater with the ET treatment in comparison to the control and JA treatments at 72 and 96 hai (Table 4), and PPO activity was significantly higher with the JA treatment compared to the control and ASM treatments at 96 hai (Table 4). For cultivar BR-18, there was no significant difference among the control, JA and ET treatments with regard to PPO activity at 0 hai or among the AJ, ASM and ET treatments at 48, 72 and 96 hai. PPO activity was significantly higher with the JA, ASM and ET treatments in comparison to the control treatment at 72 and 120 hai (Table 4).

For BRS-229, PAL activity was significantly higher with the ET treatment in comparison to the other treatments at 0 hai (Table 5). PAL activity was significantly higher for the control treatment in comparison to the JA, ASM and ET treatments at 48 hai, ASM at 72 hai and ASM and ET treatments at 96 hai (Table 5). There was no significant difference among the treatments for PAL activity at 120 hai (Table 5). For cultivar BR-18, PAL activity was significantly higher with the control and ET treatments in comparison to JA and ASM at 0 hai (Table 5). PAL activity was significantly higher with the control and JA treatments in comparison to the ASM treatment at 72 hai and in comparison to the ASM and ET treatments at 96 hai. For PAL activity, there was no significant difference among the treatments at 48 and 120 hai (Table 5).

For BRS-229, CHI activity was significantly higher for the control and JA treatments in comparison to the ET treatment at 48 hai (Table 6). At 72 hai, $\mathrm{CHI}$ activity was significantly higher for the control and ASM treatments in comparison to the JA treatment (Table 6). There was no significant difference in $\mathrm{CHI}$ activity among the treatments at 0,96 and 120 hai (Table 6). For cultivar BR-18, CHI 


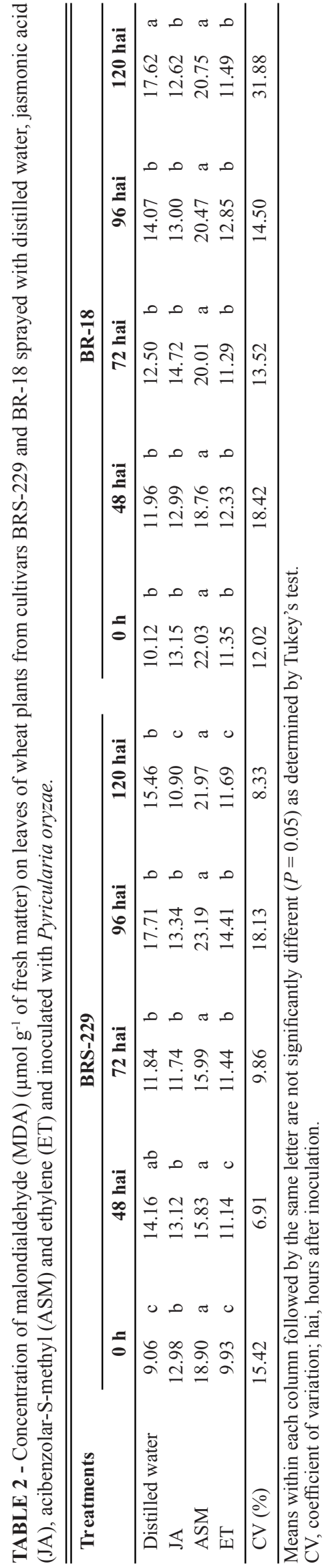

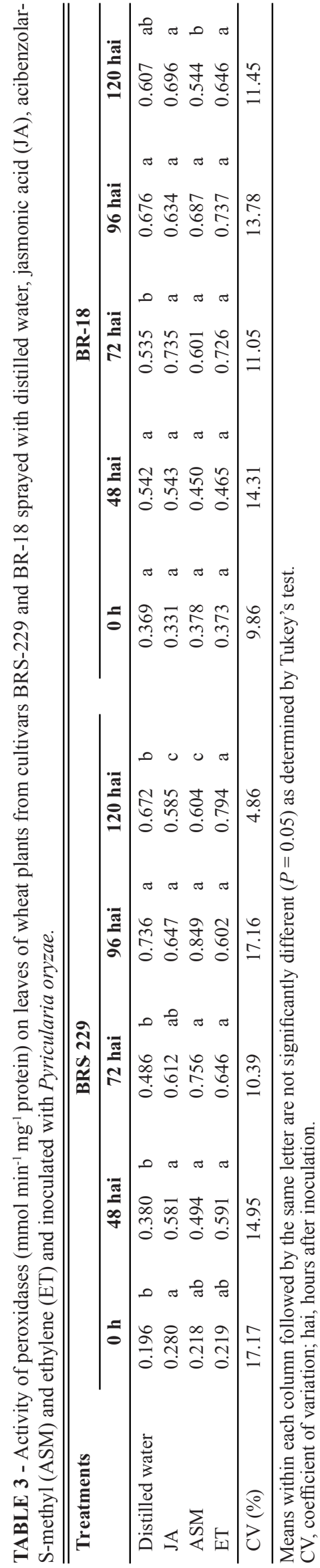

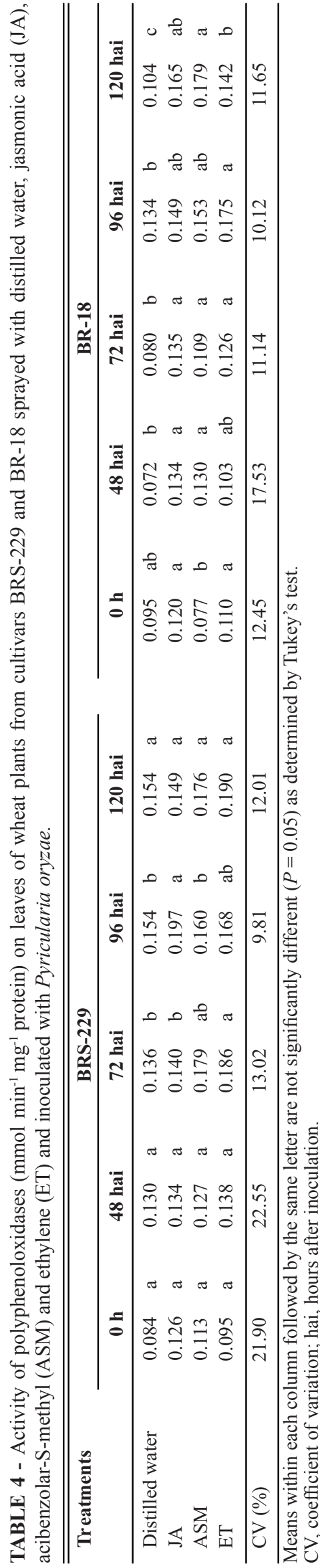



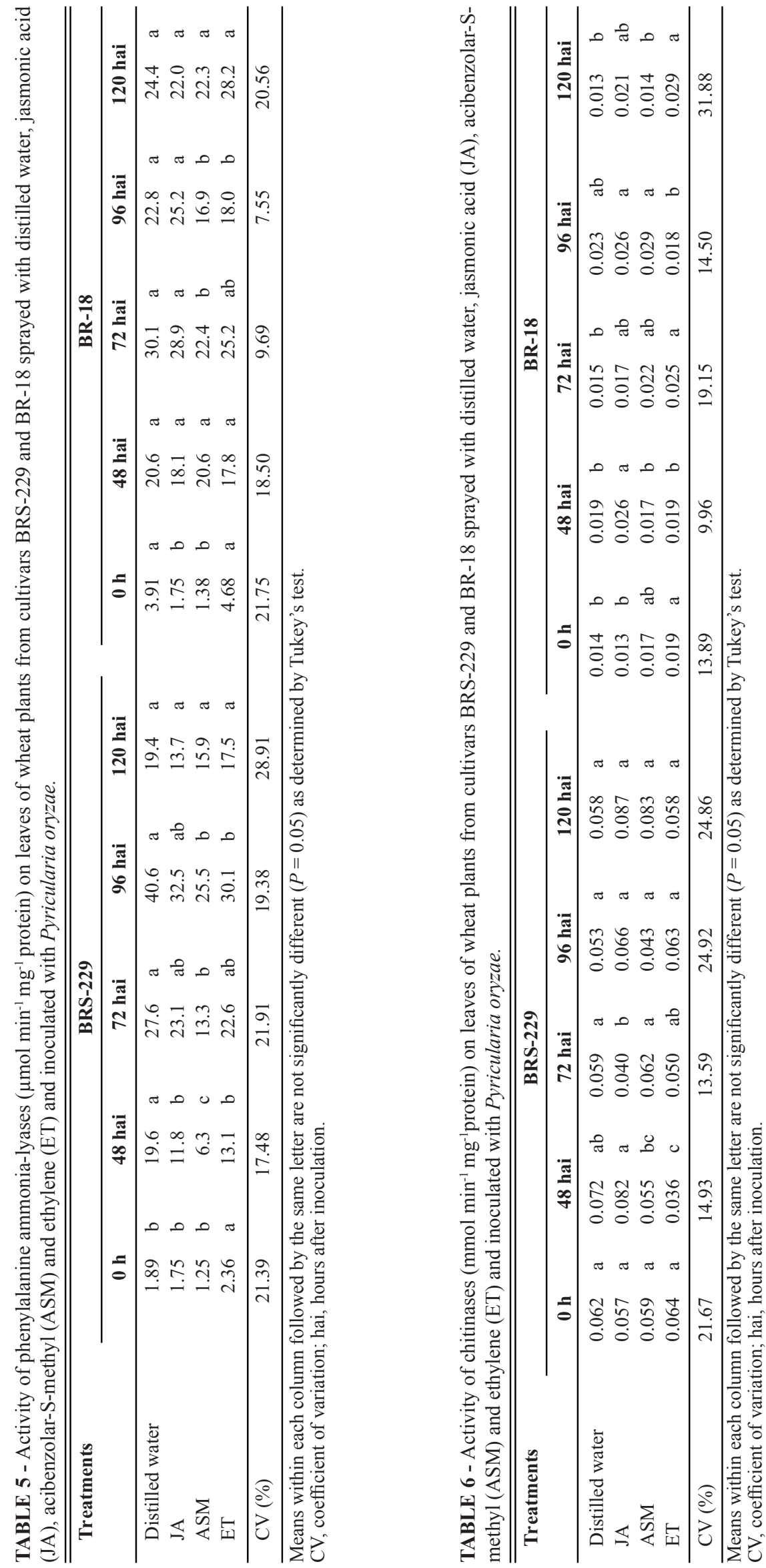
activity was significantly higher with the ET treatment compared to the control treatment at 0,72 and 120 hai, for the JA treatment in comparison to ASM, ET and control treatments at 48 hai, for the JA and ASM treatments in relation to the ET treatment at 96 hai and for the ET treatment in comparison to the control and ASM treatments at 120 hai (Table 6).

For BRS-229, there was no significant difference among the treatments for GLU activity at 48 and 96 hai and for BR-18 at 0, 48 and 120 hai (Table 7). For BRS-229, GLU activity was significantly higher with the JA and ASM treatments in comparison to the control and ET treatments at 0 hai, for the ET treatment in comparison to the control and JA treatments at 72 hai and JA and the ET treatments in comparison to the control treatment at 120 hai (Table 7). For cultivar BR-18, GLU activity was significantly higher with the ASM and ET treatments in comparison to the control treatment at 72 hai and with the JA treatment in comparison to the control treatment at 96 hai (Table 7).

For both cultivars, LOX activity was significantly higher with the ASM treatment in comparison to the other treatments at all evaluation times (Table 8).

\section{DISCUSSION}

Many studies have investigated the use of ASM and the phytohormones AJ and ET to increase the basal level of resistance of various plant species against infection caused by root and foliar pathogens (Faize et al., 2004; Mandal et al., 2006; Belhadj et al., 2008; Vechet et al., 2009). However, with regard to the wheat-Pyricularia oryzae interaction, this is the first study, to the best of our knowledge, to present evidence that JA and ET can trigger wheat resistance to blast.

In the present study, spraying the plants of cultivars BRS-229 and BR-18 with JA and ET reduced NL and AUBPC, without affecting IP and LS, indicating that these phytohormones positively regulated the resistance of wheat to blast. Although the area under disease progress curve provides information on the effect of host defense mechanisms in reducing disease intensity during a certain period of time (Campbell \& Madden, 1990), the decrease in NL suggests that mechanisms of resistance may be operating in P. oryzae pre-penetration and post-penetration events. Therefore, reductions in NL and AUBPC suggest that the phytohormones JA and ET can modulate wheat plant defense mechanisms to respond more quickly and in an effective way against $P$. oryzae infection, mainly by increasing the basal activity levels of POX, PPO, CHI and GLU. Mandal et al. (2006) observed a reduction of the karnal bunt symptoms, which is caused by Tilletia indica, on wheat plants sprayed with JA due to a balance between proteases and protease inhibitors in association with intense tissue lignification. Many other studies have demonstrated that ET can increase host resistance to diseases. As reported by Penmetsa et al. (2008), the EIN2 protein in the leaves of Medicago truncatula increased the resistance against Phytophthora infestans infection.

Even though the use of ASM can decrease the intensity of some diseases (Vechet et al., 2009; Dann et al., 1998) by triggering SAR in the same spectrum of resistance as pathogen-induced SAR or through exogenous salicylic acid application (Ryals et al., 1996; Vlot et al., 2009), this SA analog was ineffective in decreasing the blast symptoms in comparison to JA and ET. Indeed, the SA and JA/ET defense pathways are often mutually antagonistic (Pieterse et al., 2012), and this appeared to be case for the wheat-P. oryzae interaction. The results of the present study corroborate the finding that SAR is more effective against biotrophic and hemibiotrophic pathogens (Anderson et al., 2004; Vlot et al., 2009), considering that the hemibiotrophic phase of $P$. oryzae is shorter than $48 \mathrm{~h}$ after which the symptoms of chlorosis followed by leaf tissue necrosis begin to appear (Rodrigues et al., 2005; Debona et al., 2012). The spray of ASM showed low efficiency to reduce wheat blast symptoms in comparison to JA and ET which can be linked to the lower defense enzyme activities determined during the time course of fungal infection.

POX is involved in the polymerization of phenolics, resulting in an increase in tissue lignification and in the production of phytoalexins and reactive oxygen species (Higara et al., 2001). Xavier Filha et al. (2011) found that POX was important in increasing the resistance of wheat plants to blast. Spraying methyl jasmonate was found to be effective in reducing the severity of rust caused by Puccinia recondita f.sp. tritici on wheat due to the higher activities of POX and CHI and increase in phenolic compounds (Haggag \& Abd-El- Kareem, 2009).

PPO participates in the oxidation of phenolic compounds, leading to the production of quinones, which are toxic to many pathogens (Campbell \& Sederoff, 1996). There was an increase in PPO activity at the advanced stages of $P$. oryzae infection in the BRS-229 plants sprayed with ET and AJ. For cultivar BR-18, higher PPO activity was found throughout the $P$. oryzae infectious process in the plants sprayed with ASM, JA and ET. In contrast to POX, PPO was found to be important for wheat resistance against blast. Potato resistance to Pectobacterium atrosepticum, P. carotovorum subsp. brasiliensis and Dickeya spp. was associated with an increase in PPO and PAL activities (Ngadze et al., 2011).

CHI and GLU catalyze the hydrolysis of chitin and $\beta$-1,3-glucan, respectively, found in the cell wall of many fungi and may also release elicitors of defense responses (Keen \& Yoshikawa, 1983). The activity of GLU increased in the plants sprayed with JA and ET, indicating the importance of this enzyme in wheat resistance to blast. According to Xue et al. (1998), POX and GLU are associated with the induction of bean resistance to infections caused by Rhizoctonia solani and Colletotrichum lindemuthianum. In the present study, CHI activity increased in the plants sprayed with ET. According to Xavier Filha et al. (2011), 

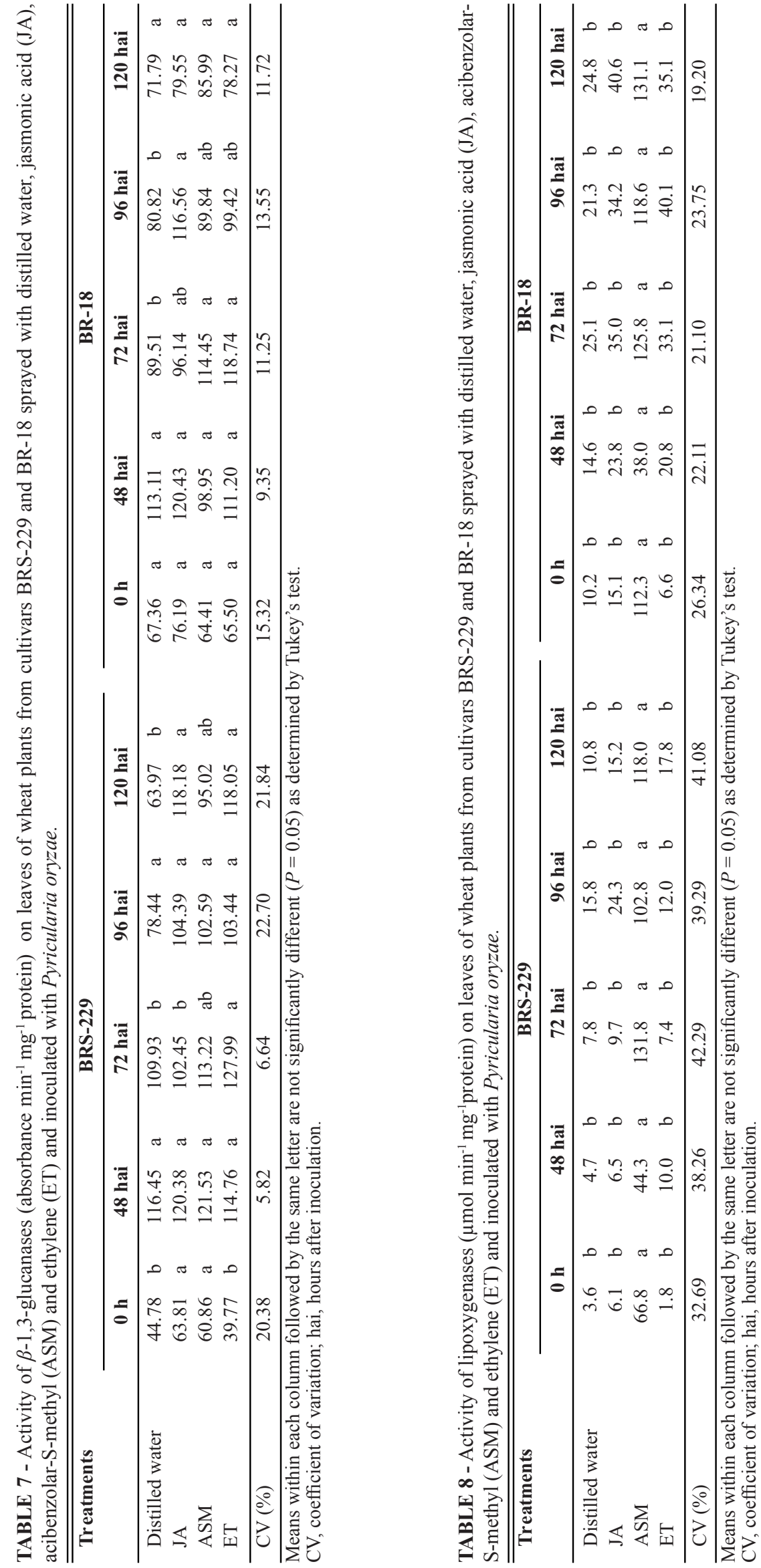
$\mathrm{CHI}$ activity was maintained at a high level in wheat plants infected with $P$. oryzae. The application of Ethephon, a source of ethylene, to grape plants infected with Erysiphe necator increased the levels of CHI transcripts (Belhadj et al., 2006).

During pathogenesis, P. oryzae causes extensive damage to the leaf cells by secreting lytic enzymes and non-specific toxins into healthy leaf tissues, increasing cellular damage (Debona et al., 2012). The low production of MDA, an indirect indicator of lipid peroxidation in the cell wall membrane (Resende et al., 2012), corroborates the reduced blast symptoms on the leaves and, indirectly, the reduced colonization by $P$. oryzae of the leaf tissues of the wheat plants sprayed with JA and ET in comparison to ASM. Reduced lipid peroxidation in the plasma membrane can also be linked to an increase in POX activity in the two cultivars sprayed with AJ and ET. Upon fungal infection, the cell membrane suffers physical damage, with the sequential LOX-initiated degradation of lipids (Alami et al., 1999). The greater wheat blast symptoms on plants of the two cultivars sprayed with ASM was linked with the higher MDA concentration and also enhanced LOX activity. Von Gonne \& Schlosser (1993) reported increased lipid peroxidation during the early colonization phase of oat leaf tissues by the necrotrophic fungi Drechslera avenae and $D$. siccans, which use reactive oxygen species to destroy leaf tissues, leading to necrosis.

The results obtained in this study indicate that spraying wheat plants with $\mathrm{AJ}$ and $\mathrm{ET}$, in contrast to ASM, was effective in reducing blast symptoms and was associated with increased activities of the defense enzymes POX, PPO, CHI and GLU.

\section{ACKNOWLEDGEMENTS}

F.A. Rodrigues thanks Conselho Nacional de Desenvolvimento Científico e Tecnológico - CNPq for his reasearch fellowship. J.A. Rios, D. Debona, R.S. Resende, W.R Moreira and C.C.L Andrade were supported by CNPq. This study was supported by grants from Coordenação de Aperfeiçoamento de Pessoal de Nível Superior - CAPES, CNPq and Fundação de Amparo à Pesquisa do Estado de Minas Gerais - FAPEMIG to F.A. Rodrigues.

\section{REFERENCES}

Abeles FB, Morgan P, Salveit M (1992) Roles and physiological effects of ethylene in plant physiology: Dormancy, growth and development. In: Abeles FB, Morgan P, Salveit M (Eds.) Ethylene in Plant Biology. San Diego, CA, USA. Academic Press. pp. 120-176.

Alami I, Jouy N, Clerivet A (1999) The lipoxygenase pathway is involved in elicitor- induced phytoalexin accumulation in plane tree (Platanus acerifolia) cell-suspension cultures. Journal of Phytopathology 147:515-519.

Anderson JP, Badruzsaufari E, Schenk PM, Manners JM, Desmond OJ, Ehlert C, Maclean DJ, Ebert PR, Kazan K (2004)
Antagonistic interaction between abscisic acid and jasmonateethylene signaling pathways modulates defense gene expression and disease resistance in Arabidopsis. Plant Cell 16:3460-3479.

Arruda MA, Bueno CRNC, Zamprogno KC, Lavorenti N, Urashima AS (2005) Reação do trigo à Magnaporthe grisea nos diferentes estádios de desenvolvimento. Fitopatologia Brasileira $30: 121-126$

Axelrod B, Cheesbrough TM, Laasko S (1981) Lipoxygenases from soybeans. Methods in Enzymology 71:441-451.

Belhadj A, Saigne C, Telef N, Cluzet S (2006) Methyl jasmonate induces defense responses in grapevine and triggers protection against Erysiphe necator. Journal of Agricultural and Food Chemistry 54:9119-9125.

Bradford MN (1976) A rapid and sensitive method for the quantitation of microgram quantities of protein utilizing the principle of protein-dye binding. Analytical Biochemistry 72:248254.

Cakmak L, Host WJ (1991) Effect of aluminum on lipid peroxidation, superoxide dismutase, catalase, and peroxide activity in root tip of soybean (Glicine max). Plant Physiology 83:463-468.

Campbell CL, Madden LV (1990) Introduction to Plant Disease Epidemiology. New York. NY, USA. John Wiley and Sons.

Campbell MM, Sederoff RR (1996) Variation in lignin contend and composition. Plant Physiology 110:3-13.

Cohen Y, Gisi U, Niderman T (1993) Local and systemic protection against Phytophthora infestans induced in potato and tomato plants by jasmonic acid and jasmonic methyl ester. Phytopathology 83:1054-1062.

Conrath U (2006) Systemic acquired resistance. Plant Signaling and Behavior 1:179-184.

Dann E, Diers B, Byrum J, Hammerschmidt R (1998) Effect of treating soybean with 2,6-dichloroisonicotinic acid (INA) and benzothiadiazole (BTH) on seed yields and the level of disease caused by Sclerotinia sclerotiorum in field and greenhouse studies. European Journal of Plant Pathology 104:271-278.

Debona D, Rodrigues FA, Rios JA, Nascimento KJT (2012) Biochemical changes in the leaves of wheat plans infected by Pyricularia oryzae. Phytopathology 102:1121-1129.

Faize M, Faize L, Koike N, Ishizaka M, Ishii H (2004) Acibenzolars-methyl-induced resistance to Japanese pear scab is associated with potentiation of multiple defense responses. Phytopathology 94:604-612.

Glazebrook J (2005) Contrasting mechanisms of defense against biotrophic and necrotrophic pathogens. Annual Review of Phytopathology 43:205-227.

Gomes FP, Garcia CH (2002) Análise de grupos de experimentos In: Gomes FP, Garcia CH (Eds.) Estatística Aplicada a Experimentos Agronômicos e Florestais. Piracicaba, SP. FEALQ. pp. 169-191.

Goulart ACP, Sousa PG, Urashima AS (2007) Danos em trigo causados pela infecção de Pyricularia grisea. Summa Phytopathologica 33:358-363.

Haggag WM, Abd-El-Kareem F (2009) Methyl jasmonate stimulates polyamines biosynthesis and resistance against leaf rust in wheat plants. Archives of Phytopathology and Plant Protection 42:16-31. 
Harman GE, Hayes CK, Lorito M, Broadway RM, Di Pietro A, Peterbauer C, Tronsmo A (1993) Chitinolytic enzymes of Trichoderma harzianum, purification of chitobiosidase and endochitinase. Phytopathology 83:313-318.

Higara S, Sasaki K, Ito H, Ohashi Y, Matsui H (2001) A large family of class III plant peroxidases. Plant and Cell Physiology 42:462-468.

Igarashi S, Utiamada CM, Igarashi LC, Kazuma AH, Lopes RS (1986) Pyricularia sp. em trigo. I. Ocorrência de Pyricularia sp. no estado do Paraná. Fitopatologia Brasileira 11:351-352.

Kar M, Miashra D (1976) Catalase, peroxidase and polyphenoloxidase activities during rice leaf senescence. Plant Physiology 57:315-319.

Keen NT, Yoshikawa M (1983) $\beta$-1,3-endoglucanase from soybean releases elicitor active carbohydrates from fungus cell walls. Plant Physiology 71:460-465.

Knoester M, Pieterse CMJ, Bol JF, Van Loon LC (1999) Systemic resistance in Arabidopsis induced by rhizobacteria requires ethylene-dependent signaling at the site of application. Molecular Plant-Microbe Interactions 12:720-727.

Koehl J, Djulic A, Kirner V, Nguyen TT, Heiser L (2002) Ethylene is required for elicition-induced oxidative burst but not for cell death induction in tobacco cell suspension cultures. Journal of Plant Physiology 129:1555-1563.

Lever M (1972) A new reaction for colorimetric determination of carbohydrates. Analytical Biochemistry 47:273-279.

Mandal KM, Pandey D, Purwar S, Singh US, Kumar A (2006) Influence of jasmonic acid as potential activator of induced resistance against karnal bunt in developing spikes of wheat. Journal of Biosciences 31:607-616.

Ngadze E, Icishahayo D, Coutinho TA, van der Waals JE (2011) The role of polyphenol oxidase, peroxidase, phenylalanine ammonia lyase, chlorogenic acid and total soluble phenols in the resistance of potatoes to soft rot. Plant Disease 96:186-192.

Penmetsa RV, Uribe P, Anderson J, Lichtenzveig J, Gish JC, Nam YW, Engstrom E, Xu K, Sckisel G, Pereira M, Baek JM, LopezMeyer M, Long SR, Harrison MJ, Singh KB, Kiss GB, Cook DR (2008) The Medicago truncatula ortholog of Arabidopsis EIN2, sickle, is a negative regulator of symbiotic and pathogenic microbial associations. Plant Journal 55:580-595.

Pieterse CMJ, van der Does D, Zamioudis C, Leon-Reyes A, van Wees SCM (2012) Hormonal modulation of plant immunity. Annual Review of Cell and Developmental Biology 28:489-521.
Resende RS, Rodrigues FA, Cavatte, PC, Martins SCV, Moreira WR, Chaves ARM, DaMatta FM (2012) Leaf gas exchange and oxidative stress in sorghum plants supplied with silicon and infected by Colletotrichum sublineolum. Phytopathology 102:892898.

Rios JA, Debona D, Duarte HSS, Rodrigues FA (2013) Development and validation of a standard area diagram set to assess blast severity on wheat leaves. European Journal of Plant Pathology 136:603-611.

Rodrigues FA, Jurick WM, Datnoff LE, Jones JB, Rollins JA (2005) Silicon infuences cytological and molecular events in compatible rice-Magnaporthe grisea interactions. Physiological and Molecular Plant Pathology 66:144-159

Ryals JA, Neuenschwander UH, Willits MG, Molina A, Steiner HY, Hunt MD (1996) Systemic acquired resistance. Plant Cell 8:1809-1819.

Shaner G, Finney RF (1997) The effects of nitrogen fertilization on the expression of show-mildwing in knox wheat. Phytopathology 67:1051-1055.

Urashima AS, Lavorenti NA, Goulart ACP, Mehta YR (2004) Resistance spectra of wheat cultivars and virulence diversity of Magnaporthe grisea isolates in Brazil. Fitopatologia Brasileira 29:511-518.

Vechet L, Burketova L, Sindelarova M (2009) A comparative study of the efficiency of several sources of induced resistance to powdery mildew (Blumeria graminis f.sp. tritici) in wheat under field conditions. Crop Protection 28:151-154.

Vlot AC, Dempsey DA, Klessig DF (2009) Salicylic acid, a multifaceted hormone to combat disease. Annual Review of Phytopathology 47:177-206.

Von Gönner M, Schlösser E, Neubacher H (1993) Evidence from electron-spin resonance for the formation of free radicals during infection of Avena sativa by Drechslera spp. Physiological and Molecular Plant Pathology 42:405-412.

Xavier Filha MS, Rodrigues FA, Domiciano GP, Oliveira HV, Silveira PR, Moreira WR (2011) Wheat resistance to leaf blast mediated by silicon. Australasian Plant Pathology 40:28-38.

Xue L, Charest PM, Jabaji-Hare H (1998) Systemic induction of peroxidases, 1,3- $\beta$ - glucanases, chitinases, and resistance in bean plants by binucleate Rhizoctonia species. Biological Control 88:359-365.

Zadoks JC, Chang TT, Konzak CF (1974) A decimal code for the growth stages of cereals. Weed Research 14:415-421. 